\title{
O potrzebie antropologicznych badań organizacyjnego wymiaru religii ${ }^{1}$
}

\author{
Agnieszka Halemba iD https://orcid.org/0000-0002-3900-4880 \\ Instytut Archeologii i Etnologii \\ Polska Akademia Nauk \\ ahalemba@iaepan.edu.pl
}

\section{Abstract \\ On the Need for Anthropological Study of the Organizational Dimension of Religion}

Qualitative research on religion often overlooks its organizational aspect, even though most of religious life takes place within an organizational framework. Religious organizations are active on many levels: they educate and control religious specialists, shape religious materiality, and in many other ways influence how relationships with the sacred are conceptualized and lived out. The organization of religious life has implications that should be studied by researchers interested in lived religion, especially when they deal with such issues as religious experience, the integrative role of religion, ritual efficacy, and the transmission of practices and beliefs.

Keywords: religion, organization, Catholic Church, methodology

Słowa kluczowe: religia, organizacja, Kościół katolicki, metodologia

U podstaw mojego podejścia leży przekonanie, że ponieważ duża część działalności religijnej jest zinstytucjonalizowana i prowadzona przez formalne organizacje [...], to badacze religii mogą się wiele nauczyć od badaczy organizacji. Ponieważ świat organizacji religijnych jest tak zróżnicowany i ponieważ wiele organizacji religijnych realizuje cele i przyjmuje struktury, które są niepodobne do tych spotykanych w firmach, na których większość badań dotyczących organizacji skupiało się do tej pory, jest równie prawdopodobne, że behawioryści organizacyjni mają wiele do nauczenia się od badaczy religii zorganizowanej.

Paul DiMaggio ${ }^{2}$

${ }^{1}$ Niniejszy artykuł powstał jako efekt rozważań będących wynikiem kilku projektów badawczych, w tym obecnie prowadzonego projektu badawczego NCN Opus 2019/33/B/HS3/02136.

${ }^{2}$ P. DiMaggio, The Relevance of Organization Theory to the Study of Religion, [w:] Sacred Companies: Organizational Aspects of Religion and Religious Aspects of Organizations, N.J. Demerath et al. (red.), New York 1998, s. 7. O ile nie zaznaczono inaczej, tłumaczenia cytatów pochodzą od Autorki. 
Dziesiątego listopada 2020 roku watykański Sekretariat Stanu opublikował Raport dotyczacy instytucjonalnej wiedzy $i$ podejmowania decyzji $w$ sprawie bytego kardynata Theodore'a Edgara McCarricka (1930-2017)3. Raport ten nie jest poświęcony ocenie dowodów potwierdzających winę McCarricka ani analizie zeznań świadków. Oczywiście te kwestie są w nim poruszane, ale najważniejszym tematem jest kto, gdzie, kiedy i skąd wiedział o przewinieniach McCarricka i w jaki sposób podejmowane były decyzje dotyczące przyznawania mu kolejnych funkcji w Kościele oraz jego przeniesień na kolejne biskupstwa, w odniesieniu do oskarżeń o przestępstwa seksualne. Raport dotyczy działań Kościoła jako organizacji mechanizmów przekazywania, zatajania i upubliczniania wiedzy oraz sposobów reagowania na konkretne oskarżenia. Już sam tytuł dokumentu pokazuje, że Kościół jest $\mathrm{w}$ nim traktowany jak organizacja, a przestępstwa seksualne są analizowane w odniesieniu do sposobów jej wewnętrznego działania. W ten sposób raport nakreśla ramy interpretacji, która pozwala dostrzec związek między organizacyjną strukturą Kościoła a działaniami jego członków. Różni się to od dotychczasowej narracji dotyczącej przestępstw seksualnych, która, jeśli w ogóle istniała, skupiała się na indywidualnej winie poszczególnych duchownych. Można powiedzieć, że w świetle Raportu potencjalnym oskarżonym staje się Kościół katolicki jako organizacja. Wydaje się, że po raz pierwszy władze kościelne w tak zdecydowany sposób pozwoliły na upublicznienie spojrzenia na Kościół jako na organizację - sieć przekazywania wiedzy i podejmowania decyzji, mającą swój personel i środki materialne, działającą w określonym celu i według pewnych reguł, nie zawsze explicite wyrażonych, ale znanych jej aktywnym członkom.

To zwrócenie uwagi na organizacyjne drogi dystrybucji wiedzy w Kościele katolickim powinno też być ważnym momentem dla nauk społecznych zajmujących się religią. Robert Orsi ${ }^{4} \mathrm{w}$ artykułach dotyczących wykorzystywania seksualnego osób małoletnich przez księży katolickich zadał pytanie: czy jest coś specyficznie katolickiego w seksualnej relacji księdza i dziecka? Udzielił na to pytanie odpowiedzi twierdzącej. Uważał też, że skandale dotyczące wykorzystania seksualnego dzieci i innych osób przez członków katolickiego kleru „wpłyną na sposób, w jaki badamy religię"5. Może tak się stać, ponieważ odkrycie mechanizmów prowadzących do nadużyć i przestępstw wśród członków kleru wymaga zrozumienia działania Kościoła jako organizacji religijnej. Dotychczas organizacyjny aspekt religii był w badaniach jakościowych nad religią zaniedbywany, jednakże obecne wyzwania mogą się przyczynić do zmiany tej sytuacji.

W odpowiedzi tym, którzy mówią, że z kryzysu wywołanego w Kościele katolickim przez seksualne wykorzystywanie nieletnich przez księży nie można się niczego nauczyć o współczesnym katolicyzmie Robert Orsi pisał, że

\footnotetext{
${ }^{3}$ https://www.vatican.va/resources/resources_rapporto-card-mccarrick_20201110_en.pdf [dostęp: 14.12.2020].

${ }^{4}$ R.A. Orsi, What is Catholic about the Clergy Sex Abuse Crisis?, [w:] K. Norget, V. Napolitano, M. Mayblin (red.), The Anthropology of Catholicism: A Reader, Oakland 2017, s. 282-292.

${ }^{5}$ https://www.trincoll.edu/NewsEvents/NewsArticles/pages/Abuse-of-Children-by-Priests-and-Nuns.aspx [dostęp: 2.12.2020].
} 
wprost przeciwnie, wszystkiego można się nauczyć. Między innymi jak osoby są formowane w tej tradycji, kiedy są jeszcze bardzo młode; jak ta formacja zostaje tak głęboko wpisana w ich ciała i wyobraźnię, że staje się subiektywną zinternalizowaną i doświadczaną obiektywnością; i jeszcze, jak zwykli katolicy żyją ze swoimi ciałami, umysłami i wyobraźniami, których w przypadku kryzysu i oderwania od Kościoła doświadczają jako oddzielnych i odseparowanych od nich samych ${ }^{6}$.

Jeśli, jak twierdzi Orsi, tak intymne kwestie, jak sposób patrzenia na własne ciało, na swój umysł czy na relacje ze świętością mogą być opisane właśnie na poziomie poszczególnych osób jako ,katolickie”, to nie można pozostawić bez odpowiedzi pytania o to, w jaki sposób takie czy inne postawy są kształtowane, także w odniesieniu do działania organizacji religijnych. Nie ma wątpliwości, że aby zrozumieć życie religijne, musimy analizować jego aspekt organizacyjny intensywniej niż do tej pory.

Mój postulat badania organizacyjnego aspektu religii nie dotyczy oczywiście wyłącznie Kościoła katolickiego. Kościół ten jest organizacją religijną, w której aspekt organizacyjny jest niezwykle jasno wyrażony - jest to globalnie działająca hierarchiczna struktura, z wyraźnie zaznaczonym centrum, ścieżkami kształcenia personelu, a przede wszystkim z przekonaniem o własnej misji i wyjątkowości w odniesieniu do relacji z transcendencją. Jednakże większość życia religijnego odbywa się w odniesieniu do różnych form zorganizowania, które są jednak zbyt rzadko brane pod uwagę we współczesnych jakościowych badaniach nad religią.

\section{Jakościowe nauki społeczne wobec organizacyjnego aspektu religii}

Dorota Hall, pisząc o socjologii religii, podkreśla, że w ostatnich latach w zasadzie we wszystkich dominujących ujęciach religia jest konceptualizowana w sposób, który wydobywa jej rolę $\mathrm{w}$ wytwarzaniu sensów, znaczeń $\mathrm{i}$ więzi ${ }^{7}$. Takie podejście do zjawisk religijnych prowadzi do wysunięcia się na plan pierwszy rozumienia religii jako zjawiska prospołecznego i nadającego sens światu. Hall zwraca uwagę, że ten sposób patrzenia na religię wywodzi się zarówno z tradycji durkheimowskiej, jak i weberowskiej - religia stanowi narzędzie integracji społecznej, a jednocześnie źródło znaczenia. W tym ujęciu organizacja religijna to efekt czy produkt uboczny funkcji integracyjnej. Przewidywane w teorii sekularyzacji zmniejszanie się znaczenia religii przyjmowano $w$ tych podejściach z obawą i wyczuwalnym żalem. Najbardziej zauważalne było to chyba w Weberowskiej koncepcji odczarowania świata i jej następcach.

Natomiast w politologii religii główny nurt badań dotyczy stosunków państwoKościół w ujęciu prawa konstytucyjnego ${ }^{8}$. W takim podejściu podstawowymi pytaniami stają się te dotyczące wolności religijnej, istnienia Kościoła państwowego czy

${ }^{6}$ R.A. Orsi, What is Catholic about..., op. cit., s. 286.

7 D. Hall, Autorefleksja i usytuowanie badawcze w socjologicznych studiach nad religia, „Studia Socjologiczne" 2020, nr 3 (238), s. 164.

${ }^{8}$ M. Potz, Perspektywy badawcze w politologii religii, „Studia Religiologica” 2019, t. 52, nr 4, s. $277-291$. 
stosunków państwo-Kościół w wymiarze organizacyjnym i finansowym . Organizacje religijne postrzegane są jak podmioty prawne, a analizowane są normy prawne i ich aplikacja. Maciej Potz proponuje alternatywne wobec powyższego podejście, w którym religia powinna być traktowana jako zjawisko społeczne motywujące ludzi do zajmowania różnego rodzaju postaw politycznych. Organizacje religijne są postrzegane jak aktorzy polityczni, realizujący własne interesy przy użyciu strategii częściowo odmiennych, a częściowo tożsamych ze stosowanymi przez aktorów świeckich ${ }^{10}$.

W tak rozumianej politologii religii Potz wymienia trzy podstawowe podejścia. W podejściu transakcyjnym, wywodzącym się z teorii racjonalnego wyboru ${ }^{11}$, organizacja religijna traktowana jest często jak „,czarna skrzynka”, bez wewnętrznego zróżnicowania. Badanie skupia się na strategiach skierowanych na zewnątrz, na pozycji danej organizacji w polu religijnym. W tym ujęciu organizacja religijna działa jak firma, która ma do sprzedania pewne dobra i musi konkurować z innymi podobnymi firmami. Indywidualne potrzeby religijne są tu uważane za wartość stałą, swego rodzaju uniwersalną cechę człowieka, a pytania badawcze dotyczą tego, czy organizacja potrafi się dostosować zarówno do tych uniwersalnych potrzeb, jak i do strategii innych organizacji operujących w tym samym środowisku.

Drugim podejściem jest perspektywa teorii ruchów społecznych, która analizuje działania organizacji mobilizujące wiernych. Przedmiotem analizy są strategie absorbowania i generowania postaw, na przykład poprzez tworzenie narracji, wykorzystywanie sieci komunikacji czy wpływanie na wybór i pozycję liderów. To podejście zwracające uwagę na fakt, że organizacje religijne, poprzez zakotwiczenia „w porządku nadprzyrodzonym", mają do dyspozycji narzędzia motywowania członków, które nie są dostępne organizacjom świeckim ${ }^{12}$. Jak pokazuję w dalszej części artykułu, jest to obserwacja kluczowa.

Trzecie podejście, nazywane przez Potza nieco myląco kulturowym, koncentruje się na relacjach między aspektem politycznym a religijnym z perspektywy psychologii jednostki i jest zanurzone w podejściach ewolucyjnych. Przykładem mogą być prace Richarda Sosisa ${ }^{13}$ na temat costly signaling, gdzie analizowana jest rola przekonań i działań religijnych w tworzeniu więzi społecznych. Potz uważa, że to podejście nie odnosi się do poziomu organizacyjnego religii. Moim zdaniem pewne zagadnienia podejmowane na przykład w odniesieniu do teorii rytuału mogą pomóc w zrozumieniu strategii organizacji religijnych ${ }^{14}$. Fakt, że Kościół katolicki stosuje alternatywne modele rytuałów w sposób, który odpowiada teorii Whitehouse'a,

${ }^{9}$ Ibidem, s. 278.

${ }^{10}$ Ibidem, s. 279-280.

${ }^{11}$ R. Finke, R. Stark, The Churching of America, 1776-1990, New Brunswick 1992.

12 M. Potz, Perspektywy..., op. cit., s. 284-285.

${ }_{13}$ R. Sosis, Do Religions Promote Cooperation? Testing Signaling Theories of Religion, [w:] J. Slone, W. McCorkle (red.), The Cognitive Science of Religion: A Methodological Introduction to Key Empirical Studies, New York 2019, s. 155-162.

${ }^{14}$ Por. H. Whitehouse, Modes of Religiosity: A Cognitive Theory of Religious Transmission, Walnut Creek, CA 2004. 
można rozpatrywać jako strategię organizacji, która chce zarządzać życiem religijnym członków w sposób efektywny.

Podejście lived religion ${ }^{15}$ (religia w życiu) wywodzi się zaś z religioznawstwa. Traktuje ono osoby wierzące nie tylko jak uczestników, ale także narratorów i interpretatorów życia religijnego. O ile w religioznawstwie pozwoliło na zwiększenie zainteresowania tym, co nie mieści się $\mathrm{w}$ doktrynach promowanych przez poszczególne organizacje religijne, o tyle $\mathrm{w}$ antropologii zainteresowanie przeżywaniem i praktykowaniem religii poza organizacyjnym kontekstem jest metodologią dominującą. To, co najczęściej pozostaje poza obszarem zainteresowania antropologów, to właśnie działania religijnych organizacji - zarówno procedury podejmowania decyzji, kształcenie kadr, struktura finansowania, jak i charakter relacji między samą ideą świętości a strukturami organizacyjnymi. Antropologia przez długi czas skupiała się na badaniu religii jako systemu znaczeń i przekonań, podążając drogą wyznaczoną przez Clifforda Geertza; ewentualnie jako obszaru przeżywania i doświadczenia, w duchu prac Thomasa Csordasa ${ }^{16}$. Aspekt organizacyjny miał niewielkie znaczenie.

Antropologia społeczna u swego zarania rozwijała się przede wszystkim jako nauka badająca społeczeństwa uznawane za silnie zinstytucjonalizowane, ale ze słabym nasyceniem organizacyjnym ${ }^{17}$. Nawet gdy w badanych społecznościach widać było wpływ organizacji rozumianych jako rozpoznawalne podmioty działające, zarządzające bądź aspirujące do zarządzania tym czy innym aspektem życia społecznego, to badacze i badaczki skupiali się przede wszystkim na instytucjach - sposobach regulacji różnych sfer życia społecznego ${ }^{18}$. Jak pisze Joel Robbins w odniesieniu do antropologii religii, ten brak organizacji w antropologicznych analizach nie był wynikiem ich nieobecności w życiu badanych społeczności, ale kwestią ich mniej lub bardziej świadomego ignorowania przez antropologów ${ }^{19}$. Organizacje takie jak Kościół, szpital czy szkoła były marginalizowane, ponieważ widziano w nich agentów zewnętrznych, wprowadzających zmianę w lokalne instytucje społeczne. Antropolodzy zaś

${ }_{15}$ R.A. Orsi, The Madonna of 115th Street: Faith and Community in Italian Harlem, 1880-1950, New Haven-London 2002; D. Hall, Lived Religion in America: Toward A History of Practice, Princeton 1997. To wyrażenie często tłumaczone jest na język polski jako „religia przeżywana”; uważam jednak, że „religia w życiu” trafniej oddaje jego sens.

${ }^{16}$ C. Geertz, Religion as a Cultural System, [w:] M. Banton (red.), Anthropological Approaches to the Study of Religion, Abingdon-on-Thames 2004, s. 1-46; T. Csordas (red.), Embodiment and Experiences: The Existential Ground of Culture and Self, Cambridge 1994.

${ }^{17}$ D.N. Gellner, E. Hirsch, Inside Organizations: Anthropologists at Work, Oxford 2001.

${ }^{18}$ We wcześniejszych pracach przedstawiłam rozróżnienia na instytucję i organizację. Organizacja to rozpoznawany społecznie podmiot działający. Organizacje są pełne wewnętrznych sprzeczności, przeciwstawnych reguł, zwalczających się wzajemnie frakcji i konkurujących ze sobą ludzi. Jednak te sploty ludzi, infrastruktur, reguł i materialności są społecznie uznawane za działające podmioty. Instytucję rozumiem natomiast w sposób bliski klasycznemu antropologicznemu rozumieniu instytucji społecznej, czyli jako społecznie ukształtowany sposób radzenia sobie z poszczególnymi wyzwaniami czy aspektami życia. Są to mechanizmy regulujące działania jednostek i grup w wielorakich kwestiach: pokrewieństwa, zaspokajania potrzeb żywieniowych, budowania różnego rodzaju relacji społecznych. Organizacje mogą też tworzyć czy promować pewne instytucje, na przykład gdy Kościół wspiera szczególną formę instytucji małżeństwa czy też proponuje nową rutynę modlitewną.

${ }_{19}$ J. Robbins, Continuity Thinking and the Problem of Christian Culture: Belief, Time, and the Anthropology of Christianity, „Current Anthropology” 2007, t. 48, z. 1, s. 5-38. 
zainteresowani byli specyfiką i lokalnością, a zmiana rozumiana była jako niszczenie kulturowej i społecznej odmienności. Analizując prace Jean i Johna Comaroffów ${ }^{20}$, Robbins pokazał, że chrześcijaństwo wprowadzane w badanych przez tych autorów społecznościach przez konkretną organizację religijną zostało praktycznie usunięte $\mathrm{z}$ ich prac. Strategią antropologicznego opisu stało się skupienie na lokalnym kwestionowaniu, sabotowaniu i podważaniu wysiłków misyjnych. Według Robbinsa Comaroffowie usunęli tym samym z centrum uwagi doświadczenie radykalnej zmiany w życiu osób nawróconych, tak jakby widoczna obecność organizacji religijnych w tym regionie i formalne przyłączanie się do nich miejscowej ludności nie skutkowały dla poszczególnych osób żadnymi zmianami.

Robbins swoją krytykę sformułował w kategoriach antropologicznej troski o ciągłość i problem tej nauki z nagłą zmianą, a przez to z chrześcijaństwem i jego teologią radykalnych przełomów: nawrócenia, zmartwychwstania i zbawienia. Jednakże jest to moim zdaniem także szersza kwestia znikania organizacji z badań antropologicznych. Antropolodzy i antropolożki skupiają się głównie na codziennych interakcjach i na głosach tych, którzy są w pozycji podporządkowania i marginalizacji ${ }^{21}$. Jak pisała Susan Wright ${ }^{22}$, władza i organizacje są natomiast często postrzegane jako narzucone odgórnie, a nawet opresyjne, i przez to niewarte czy niegodne antropologicznej analizy.

Oczywiście obecnie istnieje antropologia organizacji ${ }^{23}$, a wielu naukowców zajmujących się zarządzaniem chętnie powołuje się na wpływy antropologiczne ${ }^{24}$. Etnografia staje się też coraz częściej narzędziem badania organizacji ${ }^{25}$. Jednakże w antropologicznych badaniach nad religią nadal widać niechęć do skupiania się na badaniu jej organizacyjnych wymiarów. Wydaje mi się, że główną przyczynę stanowi tu poczucie, że organizacyjny aspekt religii jest niejako mniej istotny od religijnego przeżywania i integrującego społecznie wymiaru rytualnego. Jednakże moim zdaniem wpływ organizacji religijnych właśnie na to religijne przeżywanie, na praktykę rytualną, na wierzenia i na społeczny wymiar religii jest tak duży, że nie mogą one pozostawać na marginesie antropologicznych zainteresowań.

Co ciekawe, w antropologii chrześcijaństwa, relatywnie nowej gałęzi antropologii religii, pewne zainteresowanie organizacjami religijnymi pojawiało się od samego początku. Podczas gdy w wielu pracach nad wspólnotami zielonoświątkowymi rozwijane były raczej takie zagadnienia, jak rola języka, performatywność, materialność,

${ }^{20}$ J. Comaroff, J.L. Comaroff, Of Revelation and Revolution, Volume 1: Christianity, Colonialism, and Consciousness in South Africa, Chicago 1991; J.L. Comaroff, J. Comaroff (red.), Civil Society and the Political Imagination in Africa: Critical Perspectives, Chicago 1999.

${ }^{21}$ W. Stoczkowski, The „Fourth Aim” of Anthropology. Between Knowledge and Ethics, „Anthropological Theory" 2008, t. 8, z. 4, s. 345-356.

22 S. Wright, Anthropology of Organizations, London-New York 1994.

23 A.C. Jiménez, The Anthropology of Organisations, Aldershot-Burlington, VT 2007.

${ }^{24}$ B. Czarniawska, Trochę inna teoria organizacji. Organizowanie jako konstrukcja sieci działań, Warszawa 2010; B. Czarniawska, Organization Theory Meets Anthropology: A Story of an Encounter, „Journal of Business Anthropology” 2012, t. 1, z. 1; M. Kostera, Antropologia organizacji: metodologia badań terenowych, Warszawa 2005.

${ }_{25}$ M. Kostera, Organizational Ethnography: Methods and Inspirations, Lund 2007. 
semiotyka czy praktyki cielesne ${ }^{26}$, już na przykład późniejsze prace Thomasa Csordasa ${ }^{27}$ odnosiły się do aspektów organizacyjnych Kościołów zielonoświątkowych. Csordas pokazał między innymi, jak do globalizacji tych Kościołów przyczyniły się utworzone przez ich sieciową organizację instytucje, takie jak ,poręczne praktyki” (portable practices) i „transportowalne przekazy” (transportable messages). Jednak postulat systematycznego badania organizacji religijnych i ich strategii został wyartykułowany dla antropologii chrześcijaństwa szczególnie mocno po zorganizowanym w 2013 roku przez Fundację Wennera-Grena sympozjum. Zwrócono wówczas uwagę, że chrześcijaństwo zbyt często było traktowane jak fenomen kulturowy w wąskim znaczeniu - pewnego rodzaju zbiór czy nawet system wartości i przekonań, kształtujących działania i postawy; za mało zaś miejsca poświęcano religijnym organizacjom, których różnorodność jest przecież w dużym stopniu odpowiedzialna za rozmaitość sposobów, w jakie wierni podchodzą do względnie jednorodnych chrześcijańskich dogmatów ${ }^{28}$. Kilka artykułów z numeru specjalnego „Current Anthropology” przedstawiającego wyniki sympozjum starało się te lukę częściowo zapełnić2 ${ }^{29}$.

Kwestia znaczenia organizacji dla chrześcijańskiej różnorodności została podjęta także w The Anthropology of Catholicism. A Reader ${ }^{30}$. Autorki wprowadzenia poświęcają wiele miejsca kwestiom kościelnych mechanizmów kontroli zarówno nad klerem, osobami świeckimi, jak i środkami materialnymi, działaniu władzy w samym centrum Kościoła oraz tworzeniu przez Kościół nowych instytucji, które mają być odpowiedzią na nowe wyzwania dostrzegane przez kościelnych menedżerów. Należy także wspomnieć o innych pracach, w których obecny jest aspekt organizacyjny. Zarówno Anna Corwin, jak i Richard Irvine śledzą wpływ zmian organizacyjnych w Kościele katolickim na osobiste modlitwy i doświadczenia mniszek i mnichów ${ }^{31}$. Jak pisze Corwin:

${ }^{26}$ W. Keane, Christian Moderns: Freedom and Fetish in the Mission Encounter, t. 1, Berkeley 2006; M.E. Engelke, M. Tomlinson, The Limits of Meaning: Case Studies in the Anthropology of Christianity, New York 2006; B. Meyer, Aesthetics of Persuasion: Global Christianity and Pentecostalism's Sensational Forms, „South Atlantic Quarterly” 2010, t. 109, z. 4, s. 741-763; B. Meyer, Mediation and Immediacy: Sensational Forms, Semiotic Ideologies and the Question of the Medium, „Social Anthropology” 2011, t. 19, z. 1, s. 23-39; M. Tomlinson, God Speaking to God: Translation and Unintelligibility at a Fijian Pentecostal Crusade, „The Australian Journal of Anthropology” 2012, t. 23, z. 3, s. 274-289.

27 T.J. Csordas, Introduction: Modalities of Transnational Transcendence, „Anthropological Theory" 2007, t. 7, z. 3, s. 259-272.

28 J. Robbins, The Anthropology of Christianity: Unity, Diversity, New Directions: An Introduction to Supplement 10, „Current Anthropology” 2014, t. 55, z. S10, s. 157-171.

29 J. Barker, The One and the Many: Church-centered Innovations in a Papua New Guinean Community, „Current Anthropology” 2014, t. 55, z. S10, s. 172-181; C. Hann, The Heart of the Matter: Christianity, Materiality, and Modernity, „Current Anthropology” 2014, t. 55, z. S10, s. 182-192; C. Handman, Becoming the Body of Christ: Sacrificing the Speaking Subject in the Making of the Colonial Lutheran Church in New Guinea, „Current Anthropology” 2014, t. 55, z. S10, s. 205-215; C. Humphrey, Schism, Event, and Revolution: The Old Believers of Trans-Baikalia, „Current Anthropology” 2014, t. 55, z. S10, s. 216-225.

${ }^{30}$ K. Norget, V. Napolitano, M. Mayblin, The Anthropology of Catholicism: A Reader, Oakland 2017.

${ }^{31}$ A.I. Corwin, Changing God, Changing Bodies: The Impact of New Prayer Practices on Elderly Catholic Nuns' Embodied Experience, „Ethos” 2012, t. 40, z. 4, s. 390-410; R. Irvine, How to Read: Lectio Divina in an English Benedictine Monastery, „Culture and Religion” 2010, t. 11, z. 4, s. 
Historia Kościoła jako instytucji [sic] głęboko wpłynęła na sposób, w jaki mniszki doświadczają swojego ciała w miarę starzenia się. [...] Ponieważ modlitewniki były redagowane, a lokalne ideologie Boga zmieniały się wraz z nimi, katolickie zakonnice w całym kraju miały okazję przekształcić swoją własną relację z Bogiem ${ }^{32}$.

Autorka pokazuje, w jaki sposób działanie organizacji religijnej, w tym przypadku przejawiające się w opracowaniu nowego modlitewnika, wpłynęło na relację zakonnic $\mathrm{z}$ bóstwem.

Celem niniejszego artykułu jest przedstawienie postulatu zwiększenia uwagi poświęcanej organizacji życia religijnego w jakościowych naukach społecznych, a przede wszystkim w antropologii. Antropologia, jako nauka posługująca się metodami badawczymi pozwalającymi na obserwację praktyk życia codziennego, powinna traktować organizacje religijne jak przestrzenie życia społecznego. Pozwoli to na wyjście poza spojrzenie na organizacje religijne jako swego rodzaju produkty uboczne pola religijnego czy też poza politologiczne traktowanie ich jak ,czarnych skrzynek". Może natomiast pogłębić proponowane przez teorie ruchów społecznych analizy strategii motywowania członków. Przede wszystkim jednak typowa dla antropologii holistyczna analiza życia religijnego nie może być pełna bez uwzględnienia różnorodności strategii organizacyjnych, relacji pomiędzy założeniami teologicznymi, praktykami zarządzania a przekonaniami członków organizacji religijnych czy też zależnościami między teologicznymi koncepcjami a instytucjami regulującymi życie społeczne. Organizacje religijne są niezwykle różnorodne, nawet w ramach jednej tradycji religijnej - wystarczy popatrzeć na różnice w zarządzaniu życiem religijnych w różnych Kościołach protestanckich, widoczne także w takich sferach, jak osobista relacja z sacrum. W moim przekonaniu antropologia społeczna posiada narzędzia, które pozwolą na zbadanie takich i innych zależności. W poniższej części pokazuję, jak kwestie poruszane w socjologicznych oraz politologicznych studiach nad organizacjami korespondują zarówno z moimi antropologicznymi obserwacjami, jak i z jakościowymi badaniami nad nadużyciami seksualnymi w Kościele katolickim, prowadzonymi przez Roberta Orsiego.

\section{Organizacje religijne $\mathrm{i}$ ich relacje $\mathrm{z}$ sacrum}

W przeglądowym artykule na temat struktur oraz form w organizacjach religijnych Hinings i Raynard ${ }^{33}$ zadają następujące pytania: Czy organizacje religijne różnią się od innego rodzaju organizacji? Jakie kwestie prowadzą do tych różnic bądź podobieństw? Czy organizacje religijne różnią się między sobą? Odpowiadjąc na te pytania, autorzy oparli się na analizie artykułów z naukowych periodyków socjologicznych, politologicznych i religioznawczych. Z tego przeglądu literatury

395-411; R. Irvine, The Mission and the Cloister. Identity, Tradition, and Transformation in the English Benedictine Congregation, „Saeculum. Jahrbuch Für Universalgesichte” 2010, t. 2, s. 289-306.

32 Ibidem, s. 406.

${ }^{33}$ C.R. Hinings, M. Raynard, Organizational Form, Structure, and Religious Organizations, [w:] P. Tracey, N. Phillips, M. Lounsbury (red.), Religion and Organization Theory, Bingley 2014, s. 159-186. 
wyciągnęli następujące wnioski: 1. Organizacje religijne są podobne do organizacji niereligijnych i w wielu aspektach podlegają podobnym procesom. 2. Jednakże od tych ostatnich różnią się tym, że mają do swojej dyspozycji narzędzia zarządzania, których efektywność wynika ze specjalnego znaczenia przydawanego systemowi wierzeń, włączając $w$ to przekonania dotyczące natury samej organizacji. 3. W organizacjach religijnych istnieje wiele specyficznych napięć: na przykład między celami religijnymi nakierowanymi na kontakt z sacrum a działaniami motywowanymi ekonomicznie ${ }^{34}$.

Autorzy wspomnianego powyżej przeglądu powołują się na starszy artykuł Hiningsa i Fostera ${ }^{35}$, w którym wprost zwrócono uwagę na wpływ wierzeń oraz watości na struktury organizacji i zarządzania. Takie kwestie, jak rola i pozycja specjalistów religijnych, stopień zaangażowania w kwestie społeczne zewnętrzne wobec samej organizacji czy kwestie wyjątkowości organizacji w jej relacji do świętości bezpośrednio wpływają na jej strukturę. Dlatego organizacje religijne są nieuchronnie odmienne od innych - ich relacje ze świętością generują pewne struktury organizacyjne.

Szczególne znaczenie mają tutaj przekonania na temat samej organizacji i jej relacji z transcendencją - czyli twierdzenia eklezjologiczne. W chrześcijaństwie to właśnie rozważania eklezjologiczne na temat roli i pozycji księży czy samej organizacji wobec sacrum sprawiają, że różne odłamy chrześcijaństwa wytwarzają tak odmienne organizacyjne modele. Różnice między praktyką działania organizacji katolickich, prawosławnych, luterańskich, reformowanych czy zielonoświątkowych wynikają między innymi z innego statusu kleru i z różnego powiązania samej organizacji kościelnej ze świętością. Oczywiście żadne z tych wyznań nie jest monolitem i także w ich wnętrzach występują różnice. Można jednak na przykład powiedzieć, że podstawowe eklezjologiczne przekonanie, które sprawia, że Kościół katolicki jest trwałą i hierarchiczną strukturą, dotyczy jego trwałego powiązania z sacrum.

Gdy prowadziłam badania wśród katolickich księży obrządku wschodniego na ukraińskim Zakarpaciu, spotykałam się z wyrażaną przez nich obawą, czy moja praca „nie zaszkodzi Kościołowi”. Rozmawiałam na tematy związane z zarządzaniem życiem religijnym, nie tylko w obrębie głównego wątku moich badań, czyli negocjacji prowadzonych wokół miejsca objawień maryjnych ${ }^{36}$. Interesowała mnie pozycja proboszczów wobec rad parafialnych, relacje jednych i drugich z lokalnym biskupem, a także sposób postrzegania Watykanu i osoby papieża. Dlaczego tak ważne było dla nich, aby moja praca nie zaszkodziła Kościołowi, skoro często opowiadali mi o działaniach także najwyższych władz kościelnych, z którymi się głęboko nie zgadzali?

${ }^{34}$ Analiza tej sytuacji na przykładzie Kościoła anglikańskiego: M. Wood, Shadows in Caves? A Re-assessment of Public Religion and Secularization in England Today, „European Journal of Sociology/ Archives Européennes de Sociologie" 2015, t. 56, z. 2, s. 241-270.

${ }_{35}$ C.R. Hinings, B.D. Foster, The Organization Structure of Churches: A Preliminary Model, „Sociology” 1972, t. 7, s. 93-106.

${ }^{36}$ A. Halemba, Negotiating Marian Apparitions: The Politics of Religion in Transcarpathian Ukraine, Budapest-New York 2015. 
Eklezjologia katolicka jest skomplikowana, co pokazuje nawet pobieżna lektura artykułu dziewiątego Katechizmu Kościoła Katolickiego ${ }^{37}$, poświęconego katolickiemu rozumieniu Kościoła. Kościół jest tam przedstawiany jako zapowiedziany od początku świata, narodzony z daru Chrystusa dla naszego zbawienia, z przebitego serca Chrystusa, który umarł na krzyżu. Kościół jest też określany jako zgromadzenie Ludu Bożego, wspólnota wszystkich, którzy uwierzyli w Chrystusa, zgromadzenie liturgiczne i wspólnota lokalna. Możemy również przeczytać, że wszelkie rozłamy ranią jedność Kościoła jako Ciała Chrystusa i nie dokonują się bez grzechów ludzi. Kościół jest zbudowany na fundamentach apostolskich i to

Chrystus sam rządzi Kościołem przez Piotra i innych Apostołów, obecnych w ich następcach, papieżu i Kolegium Biskupów. Jedyny Kościół Chrystusowy, który wyznajemy w Symbolu wiary, jako jeden, święty powszechny i apostolski [...] trwa w Kościele powszechnym, rządzonym przez następcę Piotra oraz biskupów pozostających z nim we wspólnocie, choć i poza jego organizmem znajdują się liczne pierwiastki uświęcenia i prawdy ${ }^{38}$.

Katechizm pełen jest różnorakich obrazów, rozważanych przez katolickich teologów. Dla mnie, jako badaczki społecznej, ważne jest przede wszystkim zrozumienie, jakie mogą być i jakie są społeczne konsekwencje tak bogatego i różnorodnego rozumienia pojęcia Kościoła. Jakie te obrazowe opisy Kościoła mają znaczenie dla wiernych i dla antropologa, który prowadzi wśród nich swoje badania? Jest to kwestia istotna, ponieważ Kościół katolicki jako organizacja poprzez skomplikowanie pojęcia „kościół” tworzy narzędzie zarządzania życiem religijnym, używając następnie tej wieloznaczności w praktyce pastoralnej. Ta wieloznaczność jest środkiem, który przyczynia się do zapewnienia ciągłości organizacyjnej. Obawa moich rozmówców, żeby „nie szkodzić Kościołowi”, mówiąc o pewnych sprawach, przez nich samych przecież uznawanych za nadużycia czy błędne interpretacje chrześcijańskich doktryn, wynikała z przekonania, że krytykując organizację kościelną, wchodzą jednocześnie w krytykę Chrystusa, czyli samej świętości. Kościół w eklezjologii katolickiej nie jest li tylko organizacją, a jest świętością samą w sobie.

Kościół stanowi też w tej eklezjologii Lud Boży, wspólnotę wiernych. Jest również każdym z jego członków. Z pewnością wielu czytelników słyszało twierdzenie, wypowiadane w odpowiedzi na zarzuty wobec tych czy innych działań władz kościelnych, że przecież „tak naprawdę” Kościół to wierni, wszyscy: i świeccy i kler, tworzący Kościół powszechny. Jest to chwyt erystyczny, rodzaj ekwiwokacji, czyli używania w jednej wypowiedzi jednego pojęcia w różnych znaczeniach, bez zaznaczania komunikacyjnie tej różnicy. W ten sposób właściwie nie sposób skrytykować organizacji religijnej, nie dokonując jednocześnie bluźnierstwa lub krytyki wiernych. W każdej dyskusji o Kościele katolickim różne rozumienia tego, czym jest ta religijna organizacja, pozostają w wirtualnej przestrzeni potencjałów jako zasoby, które

${ }^{37}$ Katechizm Kościoła Katolickiego (dalej: KKK), http://www.katechizm.opoka.org.pl/rkkkI-2-3. htm [dostęp: 16.12.2020].

${ }^{38}$ KKK, 869-870. 
mogą zostać zmobilizowane w odpowiednim momencie ${ }^{39}$. Kościół jest Ciałem Chrystusa, Ludem Bożym, Naszą Matką, organizacją hierarchiczną i tajemnicą soteriologiczną, by wymienić tylko kilka z nich, a każde z tych znaczeń może być wysunięte na pierwszy plan w konstruowaniu różnego rodzaju argumentów w odmiennych kontekstach historycznych i politycznych.

Rozumienie Kościoła katolickiego jako jednej struktury organizacyjnej, której władza jest bezpośrednio powiązana $\mathrm{z}$ transcendencją, to jedna $\mathrm{z}$ najważniejszych cech katolicyzmu, odpowiedzialna za wiele $\mathrm{z}$ unikatowych cech tej denominacji. W pewnym wywiadzie kardynał Ratzinger, późniejszy papież Benedykt XVI, wyraził ubolewanie, że katolicy potrafią zapomnieć o tym, iż podstawowe struktury Kościoła są ustanowione przez Boga i przez to nienaruszalne ${ }^{40}$. W ten sposób przypomniał wierzącym, że boska wola jest połączona ze strukturą organizacji religijnej. Fakt ten pokazuje, że organizacja religijna może być dla swoich członków najwyższą wartością samą w sobie, wcieleniem świętości Boga, i musi być chroniona.

Oczywiście to, co powyżej napisałam, zostało już powiedziane przez wiele osób, w tym katolickich teologów, zwłaszcza tych niepokornych, mających często kłopoty z powodu stawiania pod znakiem zapytania świętości i nienaruszalności struktur kościelnych $^{41}$. Mnie interesuje jednak praktyczne znaczenie działania Kościoła jako organizacji dla codziennego życia religijnego wiernych.

Wracając do kwestii przestępstw seksualnych: opierając się na rozmowach i obserwacji prowadzonej wśród osób wykorzystywanych przez księży, Orsi stwierdził, że są takie cechy katolicyzmu, które sprawiają, że tego typu przestępstwa powinny być postrzegane jako część większego systemu ${ }^{42}$. Rozmówcy Orsiego twierdzili, że zostali wykorzystani ,po katolicku”. Co to oznaczało? Po pierwsze, samo miejsce wykorzystania było dla nich miejscem konotowanym religijnie - od konfesjonału po zakrystię czy salę katechetyczną. Po drugie, interpretacja postaci księdza jako reprezentującego fizyczną obecność Chrystusa poprzez rolę w sakramentach, a szczególnie Eucharystii, sprawiała, że pojawiała się pewnego rodzaju intymność między księżmi a wiernymi. Interpretacja pozycji księdza jako reprezentanta Chrystusa na ziemi w opinii Orsiego promuje coś w rodzaju kultu księdza, który nie może czynić niczego złego ${ }^{43}$. Jest to jeszcze jeden element pochodny konceptualizacji Kościoła jako świętości.

Kapłani katoliccy, według Maxa Webera, są doskonałym przykładem władzy usankcjonowanej charyzmatem urzędu ${ }^{44}$. Kościół jest tu rozumiany jako organizacyj-

${ }^{39}$ Por. J. Bialecki, Virtual Christianity in an Age of Nominalist Anthropology, „Anthropological Theory" 2012, t. 12, z. 3, s. 295-319.

${ }^{40}$ V. Messori, J. Ratzinger, The Ratzinger Report: An Exclusive Interview on the State of the Church, San Francisco 1985, s. 45-46.

${ }^{41}$ Przykładem niech będzie tu Hans Küng, szwajcarski teolog, któremu zostało odebrane prawo nauczania na katolickich uniwersytetach. Por. H. Küng, Unfehlbar. Eine Anfrage, Zürich-Einsiedeln-Köln 1970.

${ }^{42}$ Ibidem.

${ }^{43} \mathrm{https}$ ://www.trincoll.edu/NewsEvents/NewsArticles/pages/Abuse-of-Children-by-Priests-and-Nuns.aspx [dostęp: 10.01.2021].

${ }^{44}$ M. Weber, On Charisma and Institution Building: Selected Papers, Chicago 1968. 
ny dyspozytor władzy mistycznej, innymi słowy jako charyzmatyczna biurokracja, gdzie władza jest legitymizowana przez transcendentną moc, administrowaną hierarchicznymi i biurokratycznymi kanałami organizacyjnymi ${ }^{45}$. W oficjalnej doktrynie Kościoła katolickiego istnieje swoista, pełna sprzeczności relacja między kapłaństwem sakramentalnym a konkretną osobą, która została wyświęcona. Z jednej strony dary Ducha Świętego związane ze święceniami są udzielane danej osobie na stałe, $\mathrm{z}$ drugiej jednak pozostają one oddzielone od danej osoby. Katechizm Kościoła Katolickiego także stwierdza, że jest to sakrament dany raz na zawsze ${ }^{46}$, jednocześnie jednak nie zabezpiecza on kapłana przed ludzkimi słabościami ${ }^{47}$. Kościół, rozumiany tu jako Ciało Chrystusa, ofiarowując danej osobie dary kapłańskie, daje jej dostęp do specyficznych i wyłącznych środków kontaktu ze świętością. Równocześnie jednak dary te są oddzielone od innych cech danej osoby ${ }^{48}$. Oznacza to, że niezależnie od tego, co dana osoba zrobi w swoim prywatnym życiu, dary kapłaństwa pozostają $\mathrm{z}$ nią. $Z$ powodu niewłaściwego postępowania kapłan może mieć zakaz prowadzenia publicznych obrzędów kultu i w związku z tym nie może przeprowadzać liturgii, spowiadać ani publicznie udzielać Eucharystii. Jednak nawet w takim przypadku nie będzie on uważany za osobę świecką i może nadal służyć jako kapłan, gdy żaden inny duchowny nie jest dostępny.

Jednakże jest oczywiste, że charyzmat, który zostaje przekazany kapłanowi, nie należy do niego jako osoby, ale do Chrystusa. W Katechizmie Kościoła Katolickiego czytamy: „Ponieważ przez pełniącego posługę święceń działa i zbawia sam Chrystus, niegodność kapłana nie jest przeszkodą dla działania Chrystusa"49. Według Webera fakt, że szczególne moce kapłana są oddzielone od jego innych cech, doprowadził do sytuacji, w której „kapłan mógłby być całkowicie zdeprawowany, nie zagrażałoby to jednak jego charyzmatycznej kwalifikacji" ${ }^{50}$. W ten sposób charyzmat urzędu jest precyzyjnie oddzielony od danej osoby, choć to właśnie poprzez dopuszczenie do urzędu w sposób nieusuwalny nadaje się jej szczególne cechy. Dla Webera Kościół katolicki jest przykładem radykalnego spojrzenia na charyzmat urzędu, w którym dary są całkowicie zdepersonalizowane, ale jednocześnie sprawiają wrażenie, jakby były cechami danej osoby. To właśnie ten status sprawia, że wierni mogą postrzegać kapłana jako jednocześnie głęboko zdeprawowanego i zasługującego na szacunek, co mogłam obserwować także podczas moich badania w Ukrainie.

Dyskusje na temat antyklerykalizmu są często budowane właśnie wokół tego przejścia między cechami osobowymi a legitymacją organizacyjną. Według obserwacji wielu antropologów krytyka zachowania kapłanów jest jednym z najbardziej rozpowszechnionych argumentów postaw antyklerykalnych, gdzie nie oznacza ona

${ }^{45}$ H. Constas, Max Weber's Two Conceptions of Bureaucracy, „American Journal of Sociology” 1958 , t. 63 , z. 4, s. $400-409$.

${ }^{46} \mathrm{KKK}, 1582$.

${ }^{47}$ Ibidem, 1550.

${ }_{48}$ M. Weber, Economy and Society, Berkeley 1978, s. 1111-1158.

${ }^{49}$ KKK, 1584.

${ }^{50}$ Ibidem, 1141. 
ani odrzucenia Kościoła jako organizacji, ani religii jako instytucji społecznej ${ }^{51}$. Wynika, z tego, iż dyskurs antyklerykalny podjęty bez wezwania do radykalnych reform jest $w$ istocie wskazaniem na pełne przyjęcie charyzmatu urzędu, w tym sensie, że konkretny urzędnik (lub nawet wszyscy) może być krytykowany bez kwestionowania szczególnej roli, jaką pełni poprzez swój urząd i związane z nim święte dary.

$\mathrm{Na}$ Zakarpaciu powszechnie znane jest powiedzenie: „Kapłan jest kapłanem, gdy ma na sobie szaty liturgiczne". Jednak większość duchownych, z którymi rozmawiałam, mówiło mi, że takie pojmowanie kapłaństwa stanowi błąd. Kapłan jest zawsze kapłanem, nie tylko wtedy, gdy stoi przed ołtarzem. Rozmówcy podkreślali jednocześnie, że księża są jak wszyscy inni - mogą popełniać błędy, mają problemy i zmartwienia, można ich traktować tak samo, jak każdego innego mieszkańca danej miejscowości. Zwracali uwagę, że szacunek, jaki ludzie okazują kapłanowi, nie powinien być rozumiany jako szacunek dla jego osoby, ale dla jego święceń. Co ciekawe, moi rozmówcy-księża podkreślali, że nie ma nic niepokojącego w jawnie uległym zachowaniu świeckich, takim jak pocałunek ręki biskupa czy nawet zwykłego księdza. O ile pozycja kapłana może być interpretowana jako powielenie statusu Chrystusa, który był jednocześnie Bogiem i człowiekiem, o tyle dodatkowo komplikuje ją fakt, że związany z nią charyzmat jest oficjalnie cechą urzędu, a nie konkretnej osoby (inaczej niż w przypadku Chrystusa). Szacunek i poddaństwo należą się temu urzędowi, a nie osobie. Jednakże w praktyce życia codziennego trudne jest przeprowadzenie tego rozdzielenia między osobą a jej ucieleśnioną funkcją. W jaki sposób można rozgraniczyć w praktyce rękę kapłana sprawującego sakramenty od jego ręki oddającej się na przykład działaniom kryminalnym?

\section{Podsumowanie}

Hubert Knoblauch ${ }^{52}$ przypomniał nie tak dawno, że skupianie się na organizacjach religijnych od dawna jest przedmiotem ostrej krytyki, sięgającej przynajmniej prac Thomasa Luckmanna ${ }^{53}$. Luckmann obawiał się, że prowadzi ono do redukcjonizmu: religia zaczyna być utożsamiana z oficjalnymi strukturami, co oznacza, że rola, jaką odgrywa w działaniach, które nie należą do formalnych organizacji ani nie są wobec nich zorientowane, jest zaniedbywana, tak samo jak jej rola wśród podmiotów spoza organizacji religijnych. Wydaje mi się jednak, że w antropologii społecznej,

${ }^{51}$ E. Badone, Breton Folklore of Anticlericalism, [w:] Religious Orthodoxy and Popular Faith in European Society, E. Baldone (red.), Princeton 1990, s. 140-162; R. Behar, The Struggle for the Church: Popular Anticlericalism and Religiosity in Post-Franco Spain, [w:] Religious Orthodoxy..., op. cit., s. 76-112; C.B. Brettell, The Priest and His People: The Contractual Basis for Religious Practice in Rural Portugal, [w:] Religious Orthodoxy..., op. cit., s. 55-75; J. de Pina-Cabral, Sons of Adam, Daughters of Eve: The Peasant Worldview of the Alto Minho, Oxford 1986; J. Riegelhaupt, Popular Anti-Clericalism and Religiosity in Pre-1974 Portugal Religion, Power and Protest in Local Communities: The Northern Shore of the Mediterranean, E.R. Wolf (red.), Berlin 1984, s. 93-114.

${ }^{52} \mathrm{H}$. Knoblauch, The Communicative Construction of Transcendence: A New Approach to Popular Religion, [w:] J. Schlehe, E. Sandkühler (red.), Religion, Tradition and the Popular: Transcultural Views from Asia and Europe, Bielefed 2014, s. 29-50.

${ }_{53}$ T. Luckmann, The Invisible Religion: The Transformation of Symbols in Industrial Society, London 1967. 
z jej naciskiem na religię w życiu (lived religion), dochodzi raczej do zaniedbywania aspektu organizacyjnego.

W jaki sposób można włączać ten aspekt w badania? Z jednej strony niezwykle ważne jest prowadzenie jakościowych badań wśród duchownych - wśród biskupów, proboszczów, diakonów i kandydatów do kapłaństwa. Może to oczywiście napotkać problemy związane $\mathrm{z}$ dostępem. Jak dotąd istnieje więcej prac prowadzonych we względnie odizolowanych wspólnotach - klasztorach i innych typach zgromadzeń ${ }^{54}$. Myślę jednak, że warto podejmować takie próby. Jednakże, nawet jeśli nie prowadzimy badań bezpośrednio wśród kleru, aspekt organizacyjny nie powinien znikać z naszych badań. Możemy na przykład skupić się na strategiach negocjacji grup czy pojedynczych osób wobec organizacji religijnej, dotyczących różnorakich kwestii: od zarządzania majątkiem wspólnot religijnych po organizację wydarzeń w kościelnych budynkach czy negocjacje dotyczące kwestii moralnych.

Jak piszą Hinings i Raynard ${ }^{55}$, badaczy organizacji i zarządzania przed zajęciem się tematami związanymi z religią przez długi czas powstrzymywało kilka kwestii: uznanie, że religia jest kwestią prywatną i że mówienie o niej jako o części życia publicznego jest nieodpowiednie; przekonanie, że waga religii we współczesnym świecie maleje; oraz założenie, że religia nie jest po prostu odpowiednim przedmiotem badań dla nauki, która ma się zajmować systematyczną analizą i u której podstaw do dziś leży teoria racjonalnego wyboru. Co ciekawe, patrząc na pierwszy i trzeci powód braku zainteresowania problematyką religii w naukach o zarządzaniu, można dostrzec jak w lustrze przyczyny, które sprawiały, że antropologia religii nie zajmowała się organizacyjnym aspektem religii. W antropologii religii przez wiele lat dominowało rozumienie religii skoncentrowane wokół pojęcia wiary ${ }^{56}$. Skupiano się na doświadczeniu religijnym, wierze i sensualności, szczególnie w kontekście chrześcijańskim. To, co odstręczało badaczy zarządzania od religii, etnologów zdawało się do niej przyciągać. Natomiast z punktu widzenia antropologii religii organizacja nie była stosownym aspektem analizy.

Zorganizowanie życia religijnego pociąga za sobą skutki, których badanie powinno się znaleźć w orbicie zainteresowań badaczy religii w życiu (lived religion), szczególnie jeśli zajmujemy się takimi kwestiami, jak doświadczenie religijne, wspólnotowa rola religii, rytuały czy transmisja praktyk i wierzeń. Moim celem nie jest podjęcie próby specyficznego zdefiniowania zjawisk religijnych. Nie zamierzam także ograniczać religii do jej aspektu organizacyjnego, ale uważam, że nie można też redukować jej do kwestii przekonań, znaczeń czy przeżywania i doświadczania. Nie da się adekwatnie opisać pozycji specjalistów religijnych i ich roli w

${ }^{54}$ S. Campbell-Jones, In Habit: An Anthropological Study of Working Nuns, London-Boston 1979; A. Corwin, op. cit.; R. Irvine, How to Read..., op. cit.; R. Irvine, The Mission and the Cloister. Identity, Tradition, and Transformation in the English Benedictine Congregation, „Saeculum. Jahrbuch Für Universalgesichte" 2010, t. 2, s. 289-306; R.J. Lester, The Immediacy of Eternity: Time and Transformation in a Roman Catholic Convent, „Religion” 2003, t. 33, z. 3, s. 201-219; R.J. Lester, Jesus in Our Wombs: Embodying Modernity in a Mexican Convent, Berkeley 2005.

${ }^{55}$ Ibidem.

${ }^{56}$ M. Ruel, Christians as Believers, [w:] J. Davis (red.), Religious Organization and Religious Experience, London 1982. 
codziennym życiu religijnym bez odniesienia się do relacji społecznych, a także do kwestii prawnych i doktrynalnych. Chcę podkreślić istotność organizacyjnego aspektu religii, sugerując, że powinniśmy sobie stawiać następujące pytania: jakie są drogi podejmowania decyzji w organizacjach religijnych i jak są one egzekwowane? Jaki jest status specjalistów religijnych i skąd się oni rekrutują? Jakie są wyobrażania na temat związku struktur organizacyjnych ze świętością? Czy trwanie organizacyjnych struktur uznawane jest za wartość? W jaki sposób finansowane są określone działania? I przede wszystkim - jak dany sposób zorganizowania życia religijnego zmienia religię dnia codziennego? Te kwestie powinny się znaleźć w centrum refleksji nad religią w jakościowych badaniach społecznych.

\section{Bibliografia}

Badone E., Breton Folklore of Anticlericalism, [w:] E. Badone (red.), Religious Orthodoxy and Popular Faith in European Society, Princeton 1990, s. 140-162.

Barker J., The One and the Many: Church-Centered Innovations in a Papua New Guinean Community, „Current Anthropology” 2014, t. 55, z. S10, s. 172-181.

Behar R., The Struggle for the Church: Popular Anticlericalism and Religiosity in Post-Franco Spain, [w:] E. Badone (red.), Religious Orthodoxy and Popular Faith in European Society, Princeton 1990, s. 76-112.

Bialecki J., Virtual Christianity in an Age of Nominalist Anthropology. „Anthropological Theory” 2012, t. 12, z. 3, s. 295-319.

Brettell C.B., The Priest and His People: The Contractual Basis for Religious Practice in Rural Portugal, [w:] E. Badone (red.), Religious Orthodoxy and Popular Faith in European Society, Princeton 1990, s. 55-75.

Campbell-Jones S., In Habit: An Anthropological Study of Working Nuns, London 1979.

Comaroff J., Comaroff J.L., Of Revelation and Revolution, Volume 1: Christianity, Colonialism, and Consciousness in South Africa, Chicago 1991.

Comaroff J.L., Comaroff J. (red.), Civil Society and the Political Imagination in Africa: Critical Perspectives, Chicago 1999.

Constas H., Max Weber's Two Conceptions of Bureaucracy, „American Journal of Sociology” 1958 , t. 63 , z. 4 , s. $400-409$.

Corwin A.I., Changing God, Changing Bodies: The Impact of New Prayer Practices on Elderly Catholic Nuns'Embodied Experience, „Ethos” 2012, t. 40, z. 4, s. 390-410.

Csordas T., Introduction: Modalities of Transnational Transcendence, „Anthropological Theory” 2007, t. 3, s. 259-272.

Csordas T. (red.), Embodiment and Experiences: The Existential Ground of Culture and Self, Cambridge 1994.

Czarniawska B., Organization Theory Meets Anthropology: A Story of an Encounter, „Journal of Business Anthropology" 2012, t. 1, z. 1, s. 118-140.

Czarniawska B., Trochę inna teoria organizacji. Organizowanie jako konstrukcja sieci działań, Warszawa 2010.

DiMaggio P., The Relevance of Organization Theory to the Study of Religion, [w:] N.J. Demerath et al. (red.), Sacred Companies: Organizational Aspects of Religion and Religious Aspects of Organizations, Oxford 1998, s. 7-23.

Engelke M.E., Tomlinson M., The Limits of Meaning: Case Studies in the Anthropology of Christianity, New York 2006. 
Finke R., Stark R., The Churching of America, 1776-1990, New Brunswick 1992.

Geertz C., Religion as a Cultural System, [w:] M. Banton (red.), Anthropological Approaches to the Study of Religion, Abingdon-on-Thames 2004.

Gellner D.N., Hirsch E., Inside Organizations: Anthropologists at Work, Oxford 2001.

Halemba A., Objawienia i duchy gór - doświadczenia, instytucje i organizacje religijne, „Prace Etnograficzne" 2014, t. 42, z. 1, s. 33-46.

Halemba A., Negotiating Marian Apparitions: The Politics of Religion in Transcarpathian Ukraine, Budapest-New York 2015.

Hall D., Lived Religion in America: Toward A History of Practice, Princeton 1997.

Hall D., Autorefleksja i usytuowanie badawcze w socjologicznych studiach nad religia, „Studia Socjologiczne" 2020, t. 238, z. 3, s. 161-186.

Handman C., Becoming the Body of Christ: Sacrificing the Speaking Subject in the Making of the Colonial Lutheran Church in New Guinea, „Current Anthropology” 2014, t. 55, z. S10, s. 205-215.

Hann C., The Heart of the Matter: Christianity, Materiality, and Modernity, „Current Anthropology" 2014, t. 55, z. S10, s. 182-192.

Hinings C.R., Foster B.D., The Organization Structure of Churches: A Preliminary Model, „Sociology" 1972, t. 7, s. 93-106.

Hinings C.R., Raynard M., Organizational Form, Structure, and Religious Organizations, [w:] P. Tracey, N. Phillips, M. Lounsbury (red.), Religion and Organization Theory, Bingley 2014, s. $159-186$.

Humphrey C., Schism, Event, and Revolution: The Old Believers of Trans-Baikalia, „Current Anthropology" 2014, t. 55, z. S10, s. 216-225.

Irvine R., The Mission and the Cloister. Identity, Tradition, and Transformation in the English Benedictine Congregation, „Saeculum. Jahrbuch Für Universalgesichte” 2010, t. 2, s. 289-306.

Irvine R., How to Read: Lectio Divina in an English Benedictine Monastery, „Culture and Religion" 2010, t. 11, z. 4, s. 395-411.

Jiménez A.C., The Anthropology of Organisations, Aldershot-Burlington, VT 2007.

Katechizm Kościoła Katolickiego (KKK), http://www.katechizm.opoka.org.pl/rkkkI-2-3.htm [dostęp: 16.12.2020].

Keane W., Christian Moderns: Freedom and Fetish in the Mission Encounter, t. 1, Berkeley 2006.

Knoblauch H., The Communicative Construction of Transcendence: A New Approach to Popular Religion, [w:] J. Schlehe, E. Sandkühler (red.), Religion, Tradition and the Popular: Transcultural Views from Asia and Europe, Bielefeld 2014, s. 29-50.

Kostera M., Antropologia organizacji: Metodologia badań terenowych, Warszawa 2005.

Kostera M., Organizational Ethnography: Methods and Inspirations, Lund 2007.

Küng H., Unfehlbar. Eine Anfrage, Zürich-Einsiedeln-Köln 1970.

Lester R.J., The Immediacy of Eternity: Time and Transformation in a Roman Catholic Convent, „Religion” 2003, t. 33, z. 3, s. 201-219.

Lester R.J., Jesus in Our Wombs: Embodying Modernity in a Mexican Convent, Berkeley 2005.

Luckmann T., The Invisible Religion: The Transformation of Symbols in Industrial Society, London 1967.

Messori V., Ratzinger J., The Ratzinger Report: An Exclusive Interview on the State of the Church, San Francisco 1985.

Meyer B., Aesthetics of Persuasion: Global Christianity and Pentecostalism's Sensational Forms, „South Atlantic Quarterly” 2010, t. 109, z. 4, s. 741-763.

Meyer B., Mediation and Immediacy: Sensational Forms, Semiotic Ideologies and the Question of the Medium, ,Social Anthropology” 2011, t. 19, z. 1, s. 23-39.

Norget K., Napolitano V., Mayblin M., The Anthropology of Catholicism: A Reader, Oakland 2017. 
Orsi R.A., The Madonna of 115th Street: Faith and Community in Italian Harlem, 1880-1950, New Haven-London 2002.

Orsi R.A., What is Catholic about the Clergy Sex Abuse Crisis?, [w:] K. Norget, V. Napolitano, M. Mayblin (red.), The Anthropology of Catholicism: A Reader, Oakland 2017, s. 282-292.

Pina-Cabral J. de, Sons of Adam, Daughters of Eve: The Peasant Worldview of the Alto Minho, Oxford 1986.

Potz M., Perspektywy badawcze w politologii religii, „Studia Religiologica” 2019, t. 52, z. 4, s. 277-291.

Riegelhaupt J., Popular Anti-Clericalism and Religiosity in Pre-1974 Portugal, [w:] E.R. Wolff (red.), Religion, Power and Protest in Local Communities: The Northern Shore of the Mediterranean, Berlin-New York 1984, s. 93-114.

Robbins J., The Anthropology of Christianity: Unity, Diversity, New Directions: An Introduction to Supplement 10, „Current Anthropology” 2014, t. 55, z. S10.

Robbins J., Continuity Thinking and the Problem of Christian Culture: Belief, Time, and the Anthropology of Christianity, „Current Anthropology” 2007, t. 48, z. 1, s. 5-38.

Ruel M., Christians as Believers, [w:] J. Davis (red.), Religious Organization and Religious Experience, London 1982.

Scott W.R., Institutions and Organizations, Thousand Oaks, CA 2001.

Sosis R., Do Religions Promote Cooperation? Testing Signaling Theories of Religion, [w:] J. Slone, W. McCorkle (red.), The Cognitive Science of Religion: A Methodological Introduction to Key Empirical Studies, New York 2019, s. 155-162.

Stoczkowski W., The „Fourth Aim” of Anthropology. Between Knowledge and Ethics, „Anthropological Theory" 2008, t. 8, z. 4, s. 345-356.

Tomlinson M., God Speaking to God: Translation and Unintelligibility at a Fijian Pentecostal Crusade, „The Australian Journal of Anthropology” 2012, t. 23, z. 3, s. 274-289.

Weber M., On Charisma and Institution Building: Selected Papers, Chicago 1968.

Weber M., Economy and Society, Berkeley 1978.

Whitehouse H., Modes of Religiosity: A Cognitive Theory of Religious Transmission, Walnut Creek, CA 2004.

Wood M., Shadows in Caves? A Re-assessment of Public Religion and Secularization in England Today, „European Journal of Sociology / Archives Européennes de Sociologie” 2015, t. 56, z. 2, s. 241-270.

Wright S., Anthropology of Organizations, London-New York 1994. 